\title{
Functional Anatomical Studies of the Elbow Movements I. Electromyographic (EMG) Analysis
}

\author{
By

\begin{abstract}
Akira NAITO, Yoshifusa SHIMIZU, Yasunobu HANDA ${ }^{1)}$, Masayoshi ICHIE $^{1)}$ and Nozomu HOSHIMIYA ${ }^{2)}$
\end{abstract}

\begin{abstract}
Department of Anatomy, Shinshu University School of Medicine, 3-1-1 Asahi, Matsumoto 390, Japan
${ }^{1)}$ Department of Anatomy, Tohoku University School of Medicine, 2-1 Seiryo-cho, Sendai 980, Japan

${ }^{2)}$ Department of Electrical Communication Engineering, Tohoku University, Aramaki, Sendai 980, Japan
\end{abstract}

- Received for Publication, August 16, $1991-$

\begin{abstract}
Key Words: Electromyography (EMG), Averaged EMG, Functional electrical stimulation (FES), Elbow flexion and extension, Elbow flexors and extensors

Summary: Activities of the elbow flexors and extensors during the movement of the elbow flexion and extension were analyzed in six normal human volunteers by electromyography (EMG). In the flexors, the majority of the muscles showed EMG activities during both the flexion and extension phases, although patterns and amplitudes of EMG activities varied from individual to individual. The biceps brachii always became less active when the forearm was in pronation. In the extensors, increase of EMG activities was observed at the period of the maximum elbow extension in the majority of cases, while no EMG activity was shown throughout the movement in some cases. During the elbow movement except at the maximum extension, the triceps brachii was almost inactive and some of their three heads, in particular the long head, often showed no EMG activity. In contrast, the anconeus was usually active, sometimes showing strong EMG activity.
\end{abstract}

Recently, the functional electrical stimulation (FES) has been investigated to restore the motor function of the paralyzed extremities caused by injury and disease of the upper motor neurons, i.e. spinal cord injuries or cerebro-vascular disorders ${ }^{7,17)}$. We have developed a computer controlled multi-channel FES system ${ }^{8,11,20)}$ and a percutaneous intramuscular electrode $^{10)}$ to obtain selective activation of individual paralyzed muscles. To control the movements of the paralyzed hand with these apparatuses, we used the neuromuscular stimulating patterns which were created on the basis of electromyographic (EMG) analyses of the hand tasks in normal human subjects, such as holding a glass and pinching a key. We have found that these stimulating patterns provided smooth and reproducible controlled movements in the paralyzed hand ${ }^{6,9,12,19)}$.

On the other hand, EMG analyses of the muscles crossing the elbow joint have been studied by many investigators ${ }^{1,2,4,14-16,18,21-23)}$. In the elbow flexors, Sullivan et al. ${ }^{22}$ ) have reported that EMGs of the biceps brachii recorded from different individuals varied in the amplitude and pattern during the same movement. Basmajian and Latif ${ }^{1)}$ have also reported that the wide range in the degree of EMG activities were observed in the biceps brachii, brachialis and brachioradialis during various elbow movements among twenty volunteers. Among the extensors, it is accepted that the anconeus is always active during various movements of the elbow ${ }^{2,4,14-16,18,21,23)}$ However, it has been reported that some of the three heads of the triceps brachii showed no EMG activity even when the elbow joint is extended ${ }^{14-16,23)}$

These findings seem to suggest that each human subject has an individual use of the muscles for the elbow movements. In this study, therefore, individual differences of EMG activities of the elbow flexors and extensors were analyzed during flexion and extension of the elbow to obtain reasonable neuromuscular stimulating patterns of the elbow movements for FES.

\section{Materials and Methods}

EMG signals from the elbow flexors and extensors of the right upper extremity were recorded in six volunteers ( 5 male, 1 female, 20 to 31 years of age). Bipolar intramuscular electrodes made of tefloncoated stainless steel wires (type $316,0.03$ inches in 
Table 1. Muscles examined and their abbreviations.

\begin{tabular}{|c|c|}
\hline Elbow flexors & Elbow extensors \\
\hline Short head of the biceps brachii: BiS & Long head of the triceps brachii : TrL \\
\hline Long head of the biceps brachii: BiL & Lateral head of the triceps brachii: TrLt \\
\hline Brachialis $\quad: \mathrm{Br}$ & Medial head of the triceps brachii : TrMd \\
\hline Brachioradialis & Anconeus $\quad:$ Anc \\
\hline
\end{tabular}

diameter) were implanted with 25 gauge injectionneedles into the muscles percutaneously for detecting EMG signals. Muscles examined and their abbreviations are shown in Table 1. Low noise amplifiers with high input impedance made by the authors were used. The EMG signals were fed into a data recorder (Shinkoh RCD-928) and a pen recorder (NEC San-ei RECTI-HORIZ-8K), and then rectified and averaged for analysis ${ }^{6,9,12,19)}$.

Movements tested were a to-and-fro motion from the maximum extension to the maximum flexion of the elbow joint with the forearm supine, midprone and prone. During experiments, the volunteer was sitting on a chair. The shoulder joint was flexed to about 45 degrees. The wrist was kept in about 45 degrees dorsiflexion, which was the functional position of the wrist joint ${ }^{13)}$. In order to obtain sufficient EMG signals ${ }^{1,4,5}$, a load (cylindrical object weighing $1.2 \mathrm{~kg}$ ) was grasped in the hand. The time course of the angle changes in the elbow joint was measured simultaneously with an electrogoniometer made of a potentiometer (Fig. 1).

\section{Results}

Figs. 2 and 3 show averaged EMGs observed during flexion and extension of the elbow with the forearm supine (a), midprone (b) and prone (c) in two different volunteers.

\section{Elbow flexors}

Compared with Figs. 2 and 3, EMG activities recorded from the muscles of the same name vary in the pattern and amplitude. For example, remarkable decrease of the activity of $\mathrm{BiS}$ is observed from the late phase of flexion to the early phase of extension in Fig. 2-a,b,c. On the contrary, increase of BiS activity is observed at the similar period in Fig. 3-a,b,c. In Fig. $2-b, \mathrm{Br}$ activity is increased markedly when the elbow joint is extended. In contrast, the maximum amplitude of $\mathrm{Br}$ activity in Fig. 3-a,b,c is observed at the maximum flexion of the elbow. These variations were usually observed among individuals.

Table 2 shows whether the muscle is "active" or "inactive" during the movement, which is divided into the flexion phase and the extension phase, in all

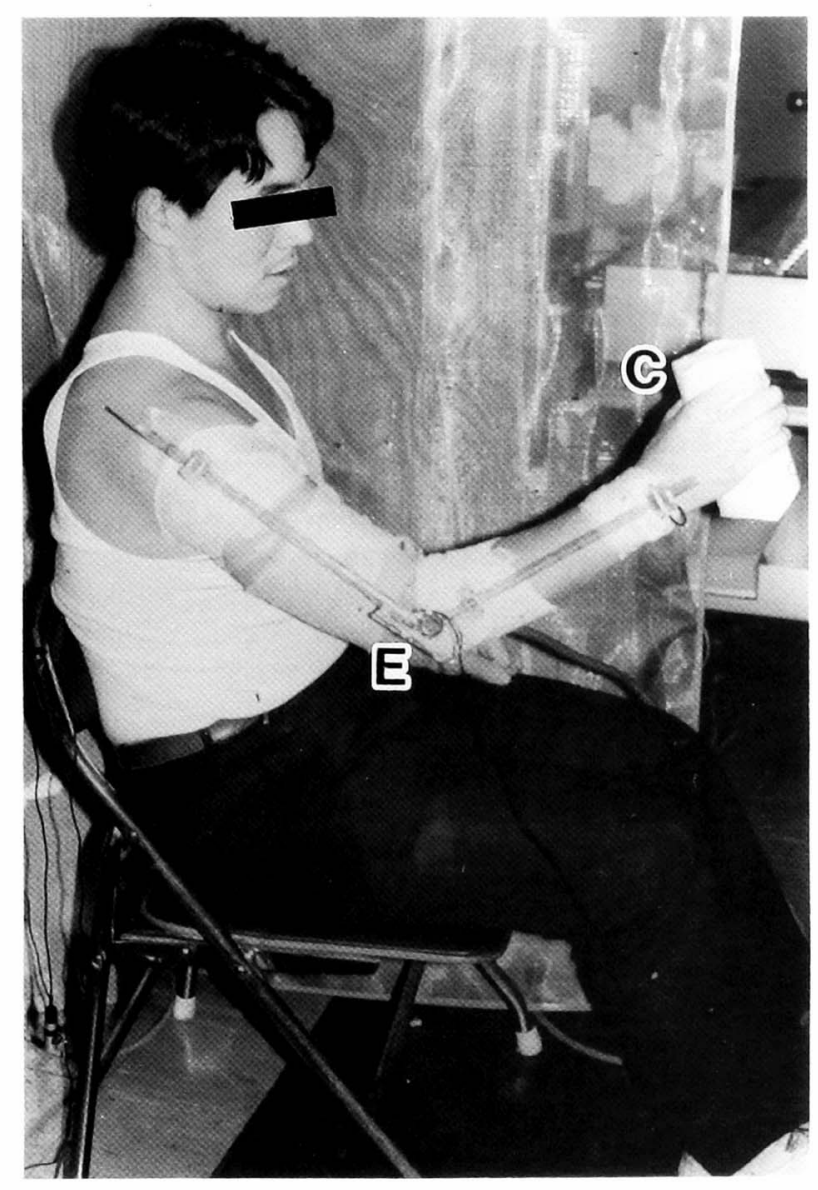

Fig. 1. Experimental situation of EMG recording during movements of the elbow flexion and extension with the forearm midprone. He holds a cylindrical object $(C)$ in the hand. An electrogoniometer (E) made of a potentiometer is put on his arm for measuring the angle changes in the elbow joint.

subjects. "Inactive" indicates that the muscle shows completely no EMG activity throughout the phase. For example, BiS in Fig. 2-c is not "inactive" but "active" during the extension phase, because slight EMG activity is seen at the middle phase of extension. While above-mentioned variations in the amplitude and pattern are present, this table indicates that the majority of the flexors are "active" during not only flexion but also extension of the elbow joint.

In Figs. 2 and 3, decrease of the amplitude of EMG activities in BiS and BiL is observed when the movement is performed with the forearm prone. This decrease was commonly observed in all subjects. 
a.

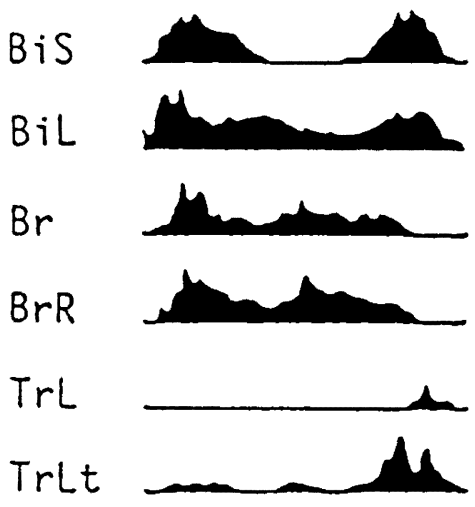

TrMd

Anc

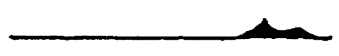

Anc

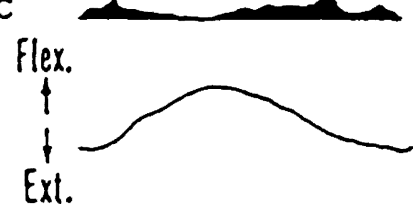

b.
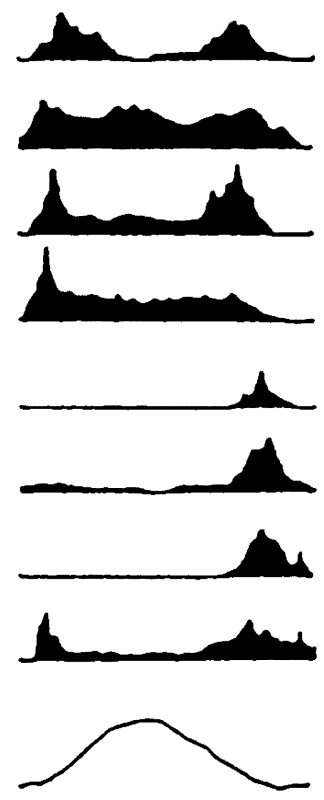

c.

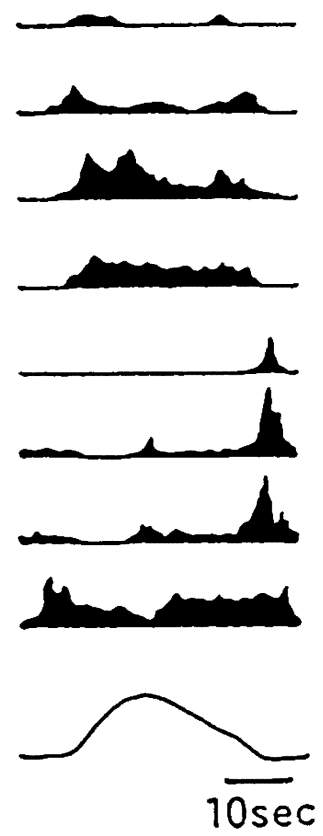

Fig. 2. Averaged EMGs observed during flexion and extension of the elbow in one subject (S.M., male, 21 years old).
a. Forearm supine.
b. Forearm midprone.
c. Forearm prone.

a.

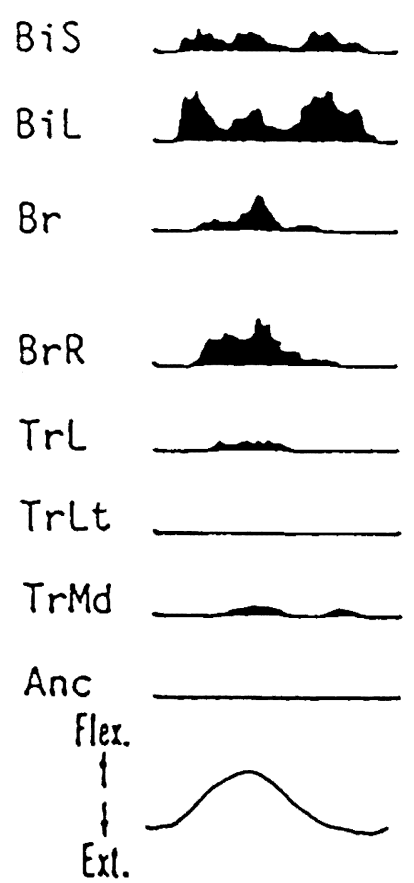

b.
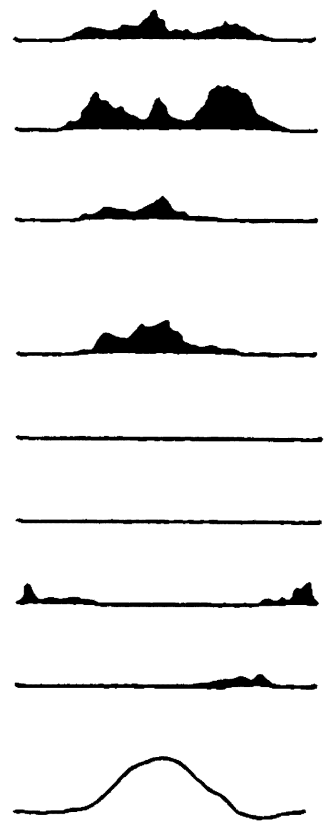

c.
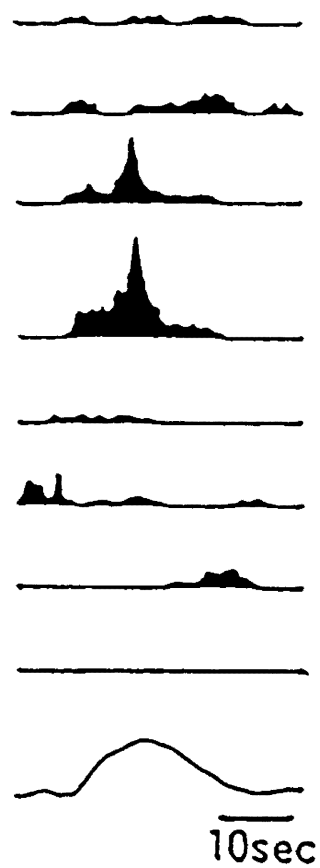

Fig. 3. Averaged EMGs obscrved during flexion and extension of the elbow in one subject (Y.I., male, 21 years old).
a. Forearm supine.
b. Forearm midprone
c. Forearm prone. 
Table 2. EMG activities of the elbow flexors during the movement of the elbow flexion and extension.

\begin{tabular}{llllllllllllllll}
\hline Name & & \multicolumn{2}{c}{ S.M. } & & Y.I. & & S.N. & J.S. & & Y.T. & & T.H. \\
\hline Phase & & F & E & F & E & F & E & F & E & F & E & F & E \\
\hline BiS & S & + & + & + & + & + & + & + & + & + & + & + & + \\
& M & + & + & + & + & + & + & + & + & + & + & + & + \\
& P & + & + & + & + & + & + & + & - & + & + & + & + \\
BiL & S & + & + & + & + & + & + & + & + & + & + & + & + \\
& M & + & + & + & + & + & + & + & + & + & + & + & + \\
& P & + & + & + & + & + & + & + & + & + & + & + & + \\
Br & S & + & + & + & + & + & - & + & + & + & + & + & + \\
& M & + & + & + & + & + & - & + & + & + & + & + & + \\
& P & + & + & + & + & + & + & + & + & + & + & + & + \\
BrR & S & + & + & + & + & + & - & + & + & + & + & + & + \\
& M & + & + & + & + & + & + & + & + & + & + & + & + \\
& P & + & + & + & + & + & + & + & + & + & + & + & + \\
\hline
\end{tabular}

+ : active - : inactive*

F: flexion phase $\quad E$ : extension phase

S: supine $\mathrm{M}$ : midprone P: prone

* "Inactive" means the muscle shows no EMG activity.

\section{Elbow extensors}

Increase of EMG activity of the extensors was usually observed at the maximum extension of the elbow regardless of the position of the forearm. For example, the maximum amplitude of EMG activity was seen at the period of the maximum extension as in TrL in Fig. 2-a, b, c, in TrLt in Figs. 2-a, b, c and 3-c, in TrMd in Figs. 2-a, b, c and 3-b, and in Anc in Figs. 2-b, c and 3-b, respectively. During the movement except at the period of the maximum extension, some of the extensors showed a slight EMG activity as in TrL in Fig. 3-a, c, TrLt in Figs. 2-a, b, c and 3-c, TrMd in Figs. 2-c and 3-a, c and Anc in Figs. $2-a, b$ and 3-b, and showed no EMG activity as in TrL in Fig. 2-a, b, c and TrMd in Figs. 2-a, b and 3-b. However, some of the extensors did not show any EMG activity throughout the movement as in TrL in Fig. 3-b, TrLt in Fig. 3-a, b and Anc in Fig. 3-a, c. The anconeus sometimes showed strong EMG activity throughout the movement as shown in Fig. 2-c.
Table 3 shows whether the muscle is "active" or "inactive" during the movement except at the maximum extension. In this table, the ratio of the number of "active" to all examined cases is $22,67,39$ and $89 \%$ in the long, lateral and medial heads of the triceps brachii, and the anconeus, respectively.

\section{Discussion}

In the present study, the majority of the flexors showed EMG activity during both the flexion and extension phase of the elbow. In contrast, the triceps brachii, considered as the chief extensor, was almost inactive except at the period of the maximum extension. The influence of gravity may be one reason for obtaining these results ${ }^{3)}$. During the movement, weight of the forearm and a load acted to extend the elbow. Thus, it has been thought that the flexors are always active to compensate this weight and the extensors are released from their role of extension.

Table 3. EMG activities of the elbow extensors during the movement except at the period of the maximum elbow extension.

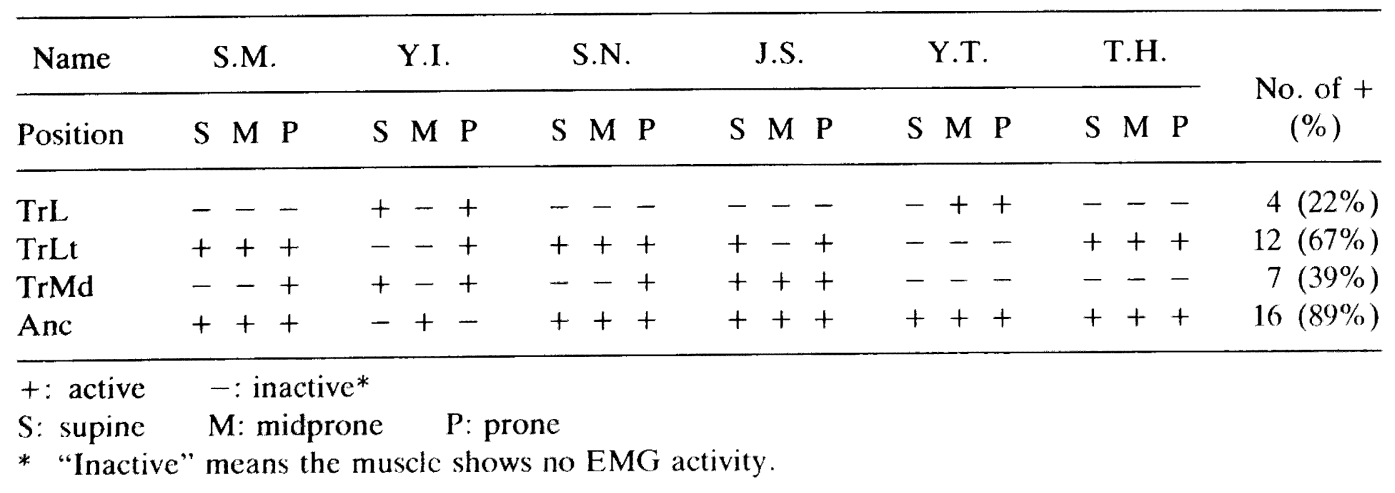


The reason why the amplitude of EMG activities of the extensors is increased at the maximum extension is considered that these muscles may act not as the elbow extensors but as the joint stabilizers ${ }^{2,3,21,22)}$.

It is well known that the biceps brachii dose not act on the prone forearm ${ }^{1,3,4,5,21)}$. In this study, the biceps brachii became less active when the forearm was in the prone position. In this regard, Basmajian and Latif ${ }^{1)}$ have described that some afferent impulses from the forearm pronators may inhibit the activity of the biceps brachii which acts not only as the elbow flexor but also as the forearm supinator.

From EMG studies of the anconeus and the three heads of the triceps brachii, Travill ${ }^{23)}$ reported that these muscles contracted independently during the elbow extension. He described that the anconeus and the medial head were always active, and the lateral head and, to a lesser extent, the long head acted as reinforcing auxiliaries. Recently, Le Bozek et al..$^{14-16)}$ and Maton et al. ${ }^{18)}$ have reported that the different extensor muscles do not come into play simultaneously and the chronology of the muscular activities of the extensors depends on the velocity and the inertia involved in the movement. They have described that threshold of muscular activity of the anconeus was lower than that of the triceps brachii, and that of the lateral head was lower than that of the medial and long head. Considering in connection with our findings (Table 3 ), it seems likely that the anconeus is the most active and the long head is the most inactive among the extensors.

In the present study, EMG activities recorded from the flexors in different individuals varied in the pattern and amplitude. These findings agree with those of Sullivan et al. ${ }^{22)}$ and also Basmajian and Latif $^{1)}$. In addition, individual variations were observed in EMG activities of the extensors. These results seem to support the concept that each human subject has an individual use of the muscles for the elbow movement. Further studies are needed to obtain reasonable neuromuscular stimulating patterns of the elbow movements for FES.

\section{Acknowledgments}

The authors wish to thank Mr. Michio Miyata and Miss Kumiko Yokouchi for their excellent assistance. Thanks are also tendered to members of our FES research group and students of Shinshu University School of Medicine for their cooperation.

\section{References}

1) Basmajian, J. V. and Latif, A.: Integrated actions and functions of the chief flexors of the elbow. J. Bone Joint
Surg., 39-A: 1106-1118, 1957.

2) Basmajian, J. V. and Griffin, W. R.: Function of anconeus muscle: an electromyographic study. J. Bone Joint Surg., 54-A: 1712-1714, 1972.

3) Basmajian, J. V.: Primary Anatomy. 8th ed., pp. 140-168., Williams and Wilkins, Baltimore, 1982.

4) Basmajian, J. V. and Deluca, C. J.: Muscles alive: Their functions revealed by electromyography. 5 th ed., pp. 265-289. Williams and Wilkins, Baltimore, 1985.

5) Beevor, C. E.: Croonian lectures on muscular movements and their representation in the central nervous system. Lancet, 1: 1715-1724, 1903.

6) Fukamachi, H., Handa, Y., Naito, A., Ichie, M., Yajima, M., Ushikoshi, K., Tsuchiya, M., Matsushita, N. and Hoshimiya, N.: Improvement of finger movement by intrinsic muscles stimulation of the hand. Proc. 9th Ann. Conf. IEEE/EMBS, 1: 361-362, 1987.

7) Handa, Y., Shimada, Y., Komatsu, S., Naito, A., Ichie, M., Nakatsuchi, Y., Yagi, R., Sugimoto, Y., Iijima, K., Futami, R. and Hoshimiya, N.: Electrically induced hand movements and their application for daily living. In: Popovic, D. (ed.): Proc. 8th Int. Symp. on External Control of Human Extremities, pp. 169-180, Yugoslav Committee for Electronics and Automation, Bergrade, 1984.

8) Handa, Y. and Hoshimiya, N.: Functional electrical stimulation for the control of the upper extremities. Med. Prog. Technol., 12: 51-63, 1987.

9) Handa, Y., Naito, A., Ichie, M., Handa, T., Matsushita, N. and Hoshimiya, N.: EMG-based stimulation patterns of FES for the paralyzed upper extremities. In: Popovic, D. (ed.): Proc. 9th Int. Symp. on External Control of Human Extremities, pp. 329-337, Yugoslav Committee for Electronics and Automation, Bergrade, 1987.

10) Handa, Y., Hoshimiya, N., Iguchi, Y. and Oda, T.: Developments of percutaneous intramuscular electrode for multi-channel FES system. IEEE Trans. Biomed. Eng., 36: 705-710, 1989.

11) Hoshimiya, N., Naito, A., Yajima, M. and Handa, Y.: A respiration controlled system for multi-joint upper extremity, IEEE Trans. Biomed. Eng., 36: 754-760, 1989.

12) Ichie, M., Handa, Y., Naito, A., Handa, T., Matsushita, N. and Hoshimiya, N.: EMG analysis of the thumb and its application to FNS. Proc. 8th Ann. Conf. IEEE/EMBS, 1: 538-540, 1986.

13) Kapandji, I. A.: Physiologie Articulaire I: Membre superieur. 1st ed., pp. 132-165, Ishiyaku Publ. Co.. Tokyo, 1986. (Translated in Japanese by Shimada, T)

14) Le Bozec, S., Maton, B. and Cnockaert, J. C.: The synergy of elbow extensor muscles during static work in man. Eur. Appl. Physiol., 43: 57-68, 1980.

15) Le Bozec, S., Maton, B. and Cnockaert, J. C.: The synergy of elbow extensor muscles during dynamic work in man. $I$. Elbow extension. Eur. Appl. Physiol., 44: 255-269. 1980.

16) Le Bozec, S. and Maton, B.: The activity of anconeus during voluntary elbow extension: The effect of lidocaine blocking of the muscle. Electromyogr. Clin. Neurophsiol., 22: $255-269,1982$.

17) Liberson, W. T., Holmquest, H. J. and Scot, D.: Functional electrotherapy: Stimulation of the peroneal nerve synchronized with the swing phase of the gait of hemiplegic patients. Arch. Phys. Med., 42: 101-105, 1961.

18) Maton, B., Le Bozec, S. and Cnokacrt. J. C.: The synergy of elbow extensor muscles during dynamic work in man. II. Breaking of elbow flexion. Eur. Appl. Physiol. 44: 271-278, 1980.

19) Matsushita, N., Handa, Y., Ichic. M., Naito, A., Handa, T. and Hoshimiya, N.: Analysis of wrist movements and its application to FNS. Proc. 8th Ann. Conf. IEEE/EMBS. 1: 
$618-619,1986$.

20) Naito, A., Handa, Y., Yajima, M., Tanaka, M., Ishikawa, S., Okubo, K. and Hoshimiya, N.: Development of a portable FES system for the paralyzed extremities. Proc. 10th Ann. Conf. IEEE/EMBS, 4: 1669-1670, 1988.

21) Pauly, J. E., Rushing, J. L. and Scheving, L. E.: An electromyographic study of some muscles crossing the elbow joint.
Anat. Rec., 159: 47-54, 1967.

22) Sullivan, W. E., Mortensen, O. A., Miles, M. and Greene L. S.: Electromyographic studies of m.biceps brachii during normal voluntary movement at the elbow. Anat. Rec., 107: 243-252, 1950

23) Travill, A. A.: Electromyographic study of the extensor apparatus of the forearm. Anat. Rec., 144: 373-376, 1962. 